\title{
RESPONSABILIDADE MORAL E OS PRINCÍPIOS DA AÇÃO EM SANTO AGOSTINHO
}

\author{
Moral Responsibility and the Principles of Action in St. Augustine
}

\author{
Matheus Jeske Vahl ${ }^{1}$
}

\begin{abstract}
RESUMO: O problema da responsabilidade moral é uma questão a ser tratada tendo em vista a qualidade das ações humanas, o que requer uma explicação da origem e do sentido do mal que eventualmente delas redunda. No pensamento tardo antigo isto é feito no horizonte de uma filosofia da mente. Em Agostinho este tema é compreendido desde o entendimento de uma faculdade anímica que garante ao homem máxima liberdade, a saber, a vontade, cujo efeito da ação é compreendido em referência a um polo de máxima transcendência - Deus, a partir de quem são compreendidos os princípios em que deve se articular a razão humana para orientar sua liberdade em coerência com a Verdade. Portanto, é na estrutura interna da mente humana que Agostinho ancora a origem e o fundamento último de toda ação moral, pela qual cada indivíduo é o único responsável frente à realidade e diante de Deus.
\end{abstract}

PALAVRAS-CHAVE: Responsabilidade; Princípios da ação; Mente; Agostinho; Deus.

ABSTRACT: The problem of moral responsibility is an issue to be addressed in view of the quality of human actions, which requires an explanation of the origin and meaning of evil that eventually results from them. In the late ancient thought, this is done on the horizon of philosophy of the mind. In Augustine, this theme is treated from the understanding of a psychical faculty that guarantees man the maximum of freedom, namely, the will, the effect of which is understood in reference to a pole of maximum of transcendence - God, from whom the principles in which the human reason must be articulated to guide his freedom, in coherence with the Truth. Therefore, it is in the internal structure of the human mind that Augustine anchors the origin and ultimate foundation of all moral action, for which each individual is solely responsible in the face of reality and in face of the God.

KEYWORDS: Responsibility; Principles of action; Mind; Augustine; God.

Quando falamos em responsabilidade moral buscamos esclarecer a que e como deve ser imputada a culpa pela "qualidade moral" das ações humanas, mais precisamente do mal que eventualmente deriva delas. Abordar este tema no contexto da antiguidade tardia,

\footnotetext{
${ }^{1}$ Doutor em filosofia pela Universidade Federal de Pelotas (UFPEL), membro do núcleo de pesquisa em filosofia medieval da UFPEL. E-mail: matheusjeskevahl@gmail.com
} 
requer adentrar no âmbito de uma "filosofia da mente" com ênfase na natureza da alma e de suas faculdades, de modo especial da razão e da vontade compreendidas num cosmos cuja chave de leitura encontra seu núcleo no conceito de Ordem. No caso específico de Santo Agostinho há um adendo: a ideia de um Deus pessoal, criador do mundo, em referência ao qual tudo o que acontece na realidade deve ser compreendido, inclusive os atos humanos.

Sem dúvida um de seus grandes legados à tradição da Filosofia Ocidental foi pôr a questão do mal enquanto desequilíbrio da realidade humana, e o consequente problema da responsabilidade moral que daí deriva, como uma reflexão acerca da natureza da alma em referência a um polo de Suma perfeição e bondade - Deus ${ }^{2}$. Agostinho parte do pressuposto que a mente humana tem uma capacidade especial de apreensão da ordo rerum pelo fato de o homem possuir, por natureza, os três "graus de ser" presentes no universo, a saber, esse, vivere, intellegere. Adere, portanto, à perspectiva neoplatônica segundo a qual a alma humana contém em si todas as expressões da realidade, bastando a compreensão dela para descortinar a essência do $\operatorname{cosmos}^{3}$. A "redução" do objeto fundamental do pensamento a estes dois pólos - Deus e a alma - demonstra que em sua visão a realidade anímica que se mostra ao pensamento não está limitada às imagens corpóreas da realidade produzidas à mente pelos sentidos, mas é composta daquilo que a alma é, do que ela deveria ser e do que ela pode ser. Só que em seu pensamento, diferente do que predomina em seus pares na antiguidade tardia, a visão da realidade anímica mencionada é compreendida com o acréscimo da imago Dei, isto é, da ideia de que na essência a alma compartilha em semelhança e imagem da perfeição e da bondade divinas.

Agostinho enfatiza que o homem possui uma posição intermediária na hierarquia dos seres. O esse e o vivere são dimensões de quem está imerso no mundo e na matéria, portanto, sujeito a sua contingência. Porém, o homem transcende esta condição por ser dotado da mens rationalis, cuja atividade lhe permite entrar em contato com o Princípio supremo que é ordenador e doador de ser à criação. Logo, em visão agostiniana, a

\footnotetext{
${ }^{2}$ Ao colocar o criacionismo com a força de um "fundamento" em sua metafísica, Agostinho o toma como uma estrutura epistêmica que compreendida à luz de sua leitura do platonismo, torna-se para ele o ponto em referência ao qual tudo deve ser pensado de modo coerente, e onde conceitos chave da metafísica clássica como a Ordem precisam ser ressignificados. Sobre este ponto ver: OLIVEIRA E SILVA, P. Ordem e Ser: ontologia da Relação em Santo Agostinho. Lisboa: Centro de Filosofia da Universidade de Lisboa, 2007, p. 15-30, AYOUB, C. N. A. Iluminação trinitária em Santo Agostinho. São Paulo: Paulus, 2011 p. 17-27 e EVANS, G. R. Agostinho sobre o Mal. São Paulo: Paulus, 1995, p. 20-25.

${ }^{3}$ Sobre os ecos no neoplatonismo e a influência direta de Plotino na estruturação desta fase do pensamento de Agostinho ver CARY, P. Augustine's Invention of the inner self: The legacy of a Cristian Platonist. Oxford: University Press, 2000, p. 30.
} 
compreensão do modo de ser inerente à alma e o que isto implica em termos de comportamento, está associado a uma visão cosmológica da realidade nos contornos de uma teodiceia. Neste sentido que seu pensamento sobre o comportamento humano tem a forma de uma "hermenêutica do real" sob a mediação da mente ${ }^{4}$. Ao transcender o plano cognitivo que está restrito à dimensão psicológica da alma, seu maior referencial passa a ser a condição do homem na realidade em relação ao ser supremo - Deus. Disto decorre uma das principais características da primeira fase de sua obra: a passagem de uma "percepção estética da Ordem para uma metafísica da Ordem que consiste precisamente na análise da natureza e funções da mente"5. Além de perceber a Ordem no curso do tempo, o pensamento precisa situar nela o homem e suas ações e, principalmente, referenciá-los a Deus. Esta visão acerca do real, aberta nos Diálogos de Cassiciaco, ganha melhor acabamento em De libero arbitrio, influenciada sobretudo pela querela de Agostinho com o maniqueísmo ${ }^{6}$.

Dada a compreensão do lugar do homem na Ordem da criação, o mal moral passa a ser o maior desafio para Agostinho conceber uma racionalidade da justiça no mundo. Foi no dualismo metafísico do maniqueísmo que ele primeiro assimilou este problema, todavia, a negatividade da matéria e o evidente fatalismo presente naquela doutrina, eram absolutamente incompatíveis com os princípios teóricos do cristianismo assumidos como seu principal referencial teórico. Assim, De libero arbitrio emerge como a obra mais relevante de um contexto em que o autor se dedica a demonstrar que o mal não pode ter uma origem metafísica, no sentido de não possuir "ser", sob pena de comprometer o princípio fundamental de sua visão de mundo, a saber, a bondade de Deus e da realidade criada e, ao mesmo tempo, que o homem não é um agente que sofre as consequências do mal que nasce na realidade, mas que em razão de sua liberdade tem o "poder" de interferir qualitativamente sobre ela.

\footnotetext{
${ }^{4}$ MEAGHER, R. Augustine: on the inner life of the mind. Indianópolis: Hackett Dublishing Company, 1998, p. 201.

${ }^{5}$ OLIVEIRA E SILVA, P. Ordem e Ser: ontologia da Relação em Santo Agostinho. Lisboa: Centro de Filosofia da Universidade de Lisboa, 2007, p. 199.

${ }^{6}$ Autores como DE CAPITANI, F. Quid et unde malum - Il problema Del male nel Giovane Agostino, prima Del ritiro a Cassiciaco. In: V Seminario del Centro di Studo Agostiniani do Perugia - "Il Misterio del Male e la Libertà: littura dei dialoghi do Agostino. Roma: Instituto Patristicum Agostinianum, 1994, p. 49 defendem que em razão de ter sido escrito em 395 o L ${ }^{\circ}$ III de De libero arbitrio está mais envolto na polêmica do antipelagianismo em florescimento na Itália do que na discussão de Agostinho com os maniqueus que deu origem à obra, pelo que a estrutura aqui mencionada corresponderia aos dois primeiros livros. A nosso ver, mesmo que o livro III traga traços de problemas de uma realidade estranha ao contexto autoral dos dois primeiros, quanto ao conteúdo é complementar e está diretamente implicado na argumentação do autor desenvolvida desde suas primeiras linhas.
} 
Desta feita, em De libero arbitrio Agostinho estabelece que a origem do mal se dá em uma operação da mente. Logo, se restrito à imanência e à contingência, à Providência não pode ser remetida a responsabilidade deste fato, imputado tão só à liberdade humana enquanto capacidade de transformação autônoma da realidade. Enquanto situado no plano da ação do homem, a origem do mal deixa de ser um problema estritamente metafísico, e passa a ser primeiramente um problema moral que se refere diretamente à relação do homem com Deus - criador e responsável pela estabilidade e harmonia da realidade. Portanto, a reflexão de Agostinho acerca do "problema do mal" o situa inicialmente em duas dimensões: (1) o mal moral é oriundo do desvio voluntário da norma que sustenta a criação, é uma atitude humana sob a qual Deus não tem qualquer responsabilidade; (2) e o mal físico que corresponde à limitação natural da criatura em sua finitude, é uma imperfeição originária fruto da temporalidade que quanto muito deixa o homem sujeito à falibilidade, mas que não pode ser tomada como origem do mal ${ }^{7}$.

Procurando se afastar de uma visão essencialista sobre o mal Agostinho termina por entendê-lo desde a qualidade das ações humanas e suas respectivas relações. A interrogação primária deixa de ser unde malum? e passa a ser quid sit male facere? Dessa forma ao invés de interrogar sobre a natureza do mal, o autor circunscreve a questão à análise da natureza dos atos humanos, considerando-o um modus faciendi capaz de ser qualificado como bom ou mau. Então, dado que a origem do mal passa pela qualidade das ações humanas, a prática da justiça e a noção de responsabilidade pelo mal praticado, dependem apenas do critério de aferição destas ações. Neste horizonte que o mal se torna o "problema humano fundamental"; primeiro em razão da culpa pela vontade livre ser sua origem, depois, porque se reduz a uma experiência de permanente sofrimento e limitação para a $\operatorname{alma}^{8}$, por último, porque passa a definir a condição da existência humana frente a Deus, o que torna este último ponto a questão principal desde a qual ele constrói sua noção de responsabilidade.

\footnotetext{
${ }^{7}$ Explica ULLMANN, R.A. Plotino: um estudo das Enéadas. 2. ed. Porto Alegre: EDIPUCRS, 2008, p. 913 que a reflexão sobre o mal não é estranha ao universo intelectual do mundo tardo antigo, todavia, é no pensamento cristão que ele toma o formato de um problema moral de primeira ordem por restringir à imanência da condição humana o peso da culpa por sua origem e consequências, onde se inclui o sofrimento a que a humanidade está constantemente submetida. Na mente judaico-cristã, o mal, originariamente, não faz parte do mundo, a não ser enquanto consequência da autonomia criatural.

8 Em Confessiones, sobretudo nos sete primeiros livros, Agostinho apresenta uma descrição desta experiência na natureza humana olhando para a própria história de sua intimidade. O cume deste processo é o sétimo livro onde sua descrição tem como ponto nevrálgico o conceito de "vontade cindida", sobre a qual comenta amplamente HORN, C. Agostinho: conhecimento, linguagem e ética. Porto Alegre: EDIPUC, 2008, p. 107-132.
} 


\section{As faculdades da ação humana: como se formam os princípios da ação moral}

Uma das características marcantes da Filosofia na antiguidade tardia é que ela tinha predominantemente a forma de uma orientação de vida onde a "vida boa" dependia em larga medida do correto conhecimento produzido e cultivado na alma. Já na composição de seus primeiros diálogos Agostinho percebe que para dar conta da realização de qualquer perspectiva de progresso espiritual, o homem precisa contemporizar a realidade de um paradoxo fincado no interior de sua natureza ${ }^{9}$ - a presença do mal na alma. Este é o grande tema de De libero arbitrio cujo objetivo inicial é a compreensão do modo de ser das faculdades anímicas.

\subsection{As paixões: a força vital do ser}

Agostinho começa a citada obra definindo a que tipo de mal sua investigação intenta esclarecer a origem. Trata-se do mal experimentado pelo homem na intimidade de sua alma. Este difere do chamado mal físico decorrente da natural e contingente mutabilidade da matéria a que todos os seres estão submetidos de uma ou outra forma, e que pode ser compreendido à luz do conceito de Providência que explica como Deus age na esfera temporal a fim de contribuir para a purificação e o crescimento das almas. Além disso, a mutabilidade e a degradação corporal fazem parte da natureza dos seres criados, do que estaria isenta unicamente a alma racional ${ }^{10}$. Deste gênero de males Deus pode ser considerado o autor, mas não daquele que Agostinho considera o grande "espinho" presente na alma do homem - o mal moral, o que realizamos mesmo nossa natureza sendo originalmente boa.

Quanto a este mal diz Agostinho que do ponto de vista metafísico "não existe um autor determinado, mas cada um é autor de suas más ações" "11. Portanto, ao empenhar-se nesta investigação o filósofo está na busca por um fundamento inconcusso das más ações humanas. Ele começa então a dissecar as operações anímicas pelas quais o homem poderia construir uma forma de ação qualificável como má. A primeira a ser interrogada

\footnotetext{
${ }^{9}$ É importante ter claro que em Agostinho o termo natureza não é tomado no sentido expresso pela physis antiga. Para ele o termo "natureza" tem um sentido metafísico ligado à substância. "Chamo natureza àquilo que também se costuma designar por substância. Por conseguinte, toda natureza é boa porque é Deus ou provém de Deus" (De lib. arb. III, 13, 36).

${ }^{10}$ AGOSTINHO. La inmortalidad del alma. In: www.augustinus.it/spanolo, I.

${ }^{11}$ AGOSTINHO. Diálogo sobre o Livre Arbitrio. Lisboa: Centro de Filosofia da Universidade de Lisboa: Imprensa Nacional-Casa da Moeda, 2001, I, 1, 1.
} 
é a aprendizagem ${ }^{12}$ : ele busca entender se a ação má não nos é ensinada por um agente externo ou se não é fruto de uma falha da nossa inteligência; rapidamente conclui que uma situação assim seria logicamente impossível, pois em seu pleno funcionamento a faculdade intelectiva não levaria o homem a uma ação prejudicial à natureza criada, portanto, a si própria. Outro ponto questionado é a lei e seu aspecto proibitivo ${ }^{13}$, onde o autor conclui que não é a proibição aquilo que torna uma coisa má, pois a lei existe justamente para proibir e evitar que se realize uma má ação, assim qualificada previamente. Conclui-se, então, que a ação má cometida por qualquer agente não decorre de nenhum tipo de coação ou de necessidade arbitrária imposta por um ente exterior, mas provém de uma realidade interna que não pode ser a própria razão ${ }^{14}$.

Isto posto, Agostinho entende que é preciso verificar nas más ações dos homens a preservação de um elemento fundamental, algo que não seja externo e contingente, mas que se encontre de modo constante em suas ações, e que diferindo da inteligência possa ser tomado como elemento universal de qualificação das ações. Ele exaure cada um dos elementos que intervém de uma forma ou outra na atividade humana de modo a determinar uma espécie de fonte originária para o mal no interior da alma, e a encontra na dimensão primária que estabelece a relação entre o homem e o mundo e do homem com Deus - a dimensão volitiva. Nela convergem num só tempo elementos de máxima imanência e realidades capazes de projetar o ser humano a um nível máxima transcendência. Em (De lib. arb. I, 3, 8) Agostinho constata que sua manifestação mais elementar é a paixão, aqui entendida como a faculdade que "domina" a alma nas ações equivocadas. Adiante, a partir de (De lib. arb. I, 4, 9) ele demonstra como ela pode se tornar um "desejo desenfreado".

\footnotetext{
${ }^{12}$ AGOSTINHO. Diálogo sobre o Livre Arbitrio. Lisboa: Centro de Filosofia da Universidade de Lisboa: Imprensa Nacional-Casa da Moeda, 2001, I, 1, 2-3.

${ }^{13}$ AGOSTINHO. Diálogo sobre o Livre Arbitrio. Lisboa: Centro de Filosofia da Universidade de Lisboa: Imprensa Nacional-Casa da Moeda, 2001, I, 3, 6-7.

${ }^{14}$ Este é um ponto em que Agostinho se afasta de uma corrente do estoicismo romano que concebia a origem da falibilidade anímica em um processo racional que termina incidindo sobre a atividade volitiva. A origem do mal estaria situada antes de tudo na esfera cognitiva da alma e não em uma operação da vontade como será defendido por ele em (De lib. arb. I). Autores como O'CONNEL, R. J. De libero arbítrio I: stoicism revisited. In: Augustian Studies I (1970), p. 50 defendem a presença de uma espécie de ecletismo estoico na construção da argumentação agostiniana neste texto. Já TORCHIA, N. J. Estoicos, Estoicismo. In: FITZGERALD, A. (org.). Diccionario de San Agustín: San Agustín a traves del tiempo. Burgos: Monte Castelo, 2001. p. 517-521 e OLIVEIRA E SILVA, P. Ordem e Ser: ontologia da Relação em Santo Agostinho. Lisboa: Centro de Filosofia da Universidade de Lisboa, 2007, p. 15-30, embora não neguem a influência estoica em seu texto, procuram evidenciar que existem diferenças cruciais entre a argumentação agostiniana e esta posição do pensamento tardo antigo, o que segundo $\mathrm{PICH}, \mathrm{R}$. H. Agostinho e a "descoberta" da vontade: primeiro estudo. In: Veritas. Porto Alegre, v.50, n.2, p. 186 se dá especialmente pelo peso dado por Agostinho à vontade livre na formação do ato moral.
} 
Em Agostinho as paixões designam o âmbito primário da vida anímica do homem, estão em nossa constituição natural e geram um efeito imediato na mente quando estimuladas por alguma forma de ser, são uma válvula pela qual absorvemos o mundo e, ao mesmo tempo, manifestamos a característica essencial do homem que é tender para fora de si. Contudo, em si mesmas elas não constituem uma ação determinada, pois o desejo supõe certa intencionalidade sobre a paixão, a saber, um conteúdo que lhe indique uma direção; quando este for vicioso e não estiver em coerência com a Verdade, temos então a formação do desejo desenfreado. Nesta situação da mente que Agostinho identifica o "primeiro sinal" da presença do mal na alma humana.

Se o que é produzido pelas paixões não for balizado por uma "racionalidade" a ação humana não será coordenada de forma virtuosa, e a alma se dispersará entre os objetos no mundo. Assim, na medida em que o desejo humano se move por essas paixões sem a coordenação racional de uma reta vontade, ele se afasta da busca pela Sabedoria e se projeta de maneira disforme sobre o mundo. Isto não significa atribuir às paixões a origem do mal de forma absoluta e restrita. A dimensão desiderativa do homem só pode ser considerada origem do mal quando equacionada com um universo de bens dispostos e quando articulada com a possibilidade de escolha da vontade sobre eles. Na medida em que somente identifica uma dimensão vital do ser humano, a paixão não é vista como origem do bem ou do mal stricto sensu, para tanto ela necessita ser assumida e coordenada pela razão e pela vontade a fim de designar uma intencionalidade ${ }^{15}$, positiva ou negativamente.

Assim, é na forma como interiormente decidimos por meio de uma operação mental coordenar nossa possibilidade de escolha sobre os bens à disposição que Agostinho identifica a origem do mal, afirmando que

desejar viver sem medo é comum a bons e maus. Mas há uma diferença: os bons desejam-no afastando o amor daquelas coisas que não podem ter sem perigo de se perderem; os maus, porém, desejam-no para desfrutar destas coisas com segurança, esforçando-se por remover o que os impeça e, por causa disso, levam uma vida facínora e criminosa ${ }^{16}$.

Agostinho entende que o mal se sedimenta na alma não como algo "aprendido", mas como algo "praticado" e interiorizado como hábito. Ele se transforma num modo de ser

\footnotetext{
${ }^{15} \mathrm{O}$ conceito de intenção ainda não está elaborado de forma mais acabada em Agostinho como em outros autores medievais, com destaque para Abelardo. Todavia, ele apresenta em obras como De Continentia uma estrutura interna do ato moral, cujas linhas mais tarde receberão um refinamento que dará origem ao conceito de intenção como o conhecemos.

${ }^{16}$ AGOSTINHO. Diálogo sobre o Livre Arbitrio. Lisboa: Centro de Filosofia da Universidade de Lisboa: Imprensa Nacional-Casa da Moeda, 2001, I, 4, 10.
} 
que passa a interferir na natureza das próprias paixões. Diz Agostinho que "a instrução é tão acidental a alma como a indumentária e o ornamento em nossos membros [...], o hábito se diz de tudo aquilo que chega a nós para que o tenhamos"17. Superar o mal nesta escala exigirá da alma transcender sua condição, algo que depois Agostinho conceberá que não é possível sem o auxílio divino. Afirma Oliveira e Silva que "desta compreensão da paixão como elemento último da natureza anímica do homem, obtém-se um princípio de máxima validade no interior da visão agostiniana acerca da origem do mal"18, todavia, isto só ficará esclarecido na medida em que se puder clarificar a relação entre a vontade como força intencional da natureza humana e a Ordem. Para tanto, é preciso ver como Agostinho concebe a relação entre inteligência e "lei eterna", cujo entendimento remonta à sua compreensão acerca da Verdade como fundamento da realidade.

\subsection{Razão: a faculdade do equilíbrio anímico}

Segundo Agostinho há na mente humana um valor supremo que ele identifica com a noção de Verdade. Trata-se de uma evidência inconcussa que aparece à razão, e frente a qual a alma é levada a compreender sua identidade mais profunda ${ }^{19}$. Nesta "interlocução" a razão descobre que há no exercício de sua própria atividade e como sua condição de possibilidade, princípios superiores a ela própria: noções imutáveis e eternas. Exemplo disso é a "lei eterna" entendida pelo autor como fundamento último não apenas da lei temporal, mas especialmente de toda ação moral. Segundo ele nada pode haver de justo no mundo que os homens não tenham feito derivar, pelo bom uso da razão, da lei eterna; definida sinteticamente como "aquela pela qual é justo que todas as coisas estejam absolutamente ordenadas" ${ }^{20}$. Seu fim é que os seres criados permaneçam em ordem preservando-os em seu estatuto ontológico. Eis a tarefa da Providência a que deve se aliar a vontade humana; a justiça da lei eterna se realiza na medida em que a alma está racionalmente ordenada, desejando e conservando os bens que não podem se perder a revelia de seu desejo.

\footnotetext{
17 AGOSTINHO. Ochenta y tres cuestiones diversas. In: Obras completas de Saint Agustín. Madrid: La Editorial Católica/BAC, 1995, tomo XL, LXXIII, 1.

${ }^{18}$ OLIVEIRA E SILVA, P. Introdução ao Diálogo sobre o Livre Arbítrio. In: AGOSTINHO. Diálogo sobre $o$ Livre Arbitrio. Lisboa: Centro de Filosofia da Universidade de Lisboa: Imprensa Nacional-Casa da Moeda, 2001, p. 52.

${ }^{19}$ AGOSTINHO. Diálogo sobre o Livre Arbítrio. Lisboa: Centro de Filosofia da Universidade de Lisboa: Imprensa Nacional-Casa da Moeda, 2001, II, 15, 16.

${ }^{20}$ AGOSTINHO. Diálogo sobre o Livre Arbitrio. Lisboa: Centro de Filosofia da Universidade de Lisboa: Imprensa Nacional-Casa da Moeda, 2001, I, 6,15.
} 
Agostinho define a consciência que se alcança com a razão como uma espécie de "forma de vida pura e superior pela qual podemos obter uma boa relação com Deus"21, pelo que afirma que se a razão "dominar e imperar sobre as demais realidades de que o ser humano se compõe, então ele estará perfeitamente ordenado" ${ }^{22}$. Neste interim não se deve deixar de ressaltar que o conceito agostiniano de vontade não se identifica com nenhuma forma de desejo racional como a boulesis aristotélica. Em sua perspectiva a razão é, por excelência, a faculdade ordenadora da alma que existe de forma independente da vontade, cabendo à atividade intelectiva o papel de efetuar juízo sobre a realidade e assim orientar a vontade. Na descrição que faz da relação das vontades anímicas em Agostinho, Gilson destaca que

\begin{abstract}
em cada sensação, a vontade tem o papel de uma força ativa sem a qual o órgão sensorial não se aplicaria ao objeto e a sensação não teria lugar [...]. Quando nossa vontade fixa um dos nossos órgãos sensoriais em algum objeto sensível, ela intervém simultaneamente em dois sentidos diferentes: primeiro, para manter o órgão em contato com o objeto, mas também para imprimir na memória a lembrança da sensação enquanto se dissipa [...]. Ela combina como quiser os elementos tomados do mundo sensível para criar um mundo imaginário segundo os movimentos livres dela. Daí, não obstante, a quantidade de erros a que nos conduz essa vontade conjuctrice mac separatricem, fazendo-nos admitir seus produtos imaginários como uma imagem fiel à realidade ${ }^{23}$.
\end{abstract}

Logo, em visão agostiniana a superioridade da espécie humana está justamente na capacidade de dar sentido aos movimentos irracionais presentes em sua atividade anímica. Tendo a razão o poder de atuar como faculdade ordenadora de toda intimidade humana, cabe a ela garantir que o ser humano não seja dominado "de fora", ou seja, ainda que possa ser atribulado corporalmente, a atividade racional garante-lhe um nível máximo de autêntica liberdade, o qual levado à sua máxima excelência permite-lhe dominar a realidade "de dentro para fora" 24 . Neste quadro que ao ter sua alma racionalmente ordenada em conformidade com a lei eterna o homem pode ser considerado sábio, pelo que diz Agostinho aos céticos: "que pensas que é viver feliz senão viver em conformidade com o que há de melhor no homem [...], e o que o há de melhor no homem é aquela porção da alma cujo domínio convém que submetam todas as demais, a saber, a mente ou razão"25.

\footnotetext{
${ }^{21}$ AGOSTINHO. Diálogo sobre o Livre Arbitrio. Lisboa: Centro de Filosofia da Universidade de Lisboa: Imprensa Nacional-Casa da Moeda, 2001, I, 7,17.

${ }^{22}$ AGOSTINHO. Diálogo sobre o Livre Arbitrio. Lisboa: Centro de Filosofia da Universidade de Lisboa: Imprensa Nacional-Casa da Moeda, 2001, I, 8,18.

${ }^{23}$ GILSON, E. Introdução ao estudo de Santo Agostinho. 2.ed. São Paulo, Paulus, 2010, p. 254-255.

${ }^{24}$ BIOLO, S. L'Autoconscienza in S. Agostino. In: Analecta Gregoriana. v.172, n.15. Roma: Editrice Pontificia Università Gregoriana, 2000, p. 124.

25 AGOSTINHO. Contra Academicos. In: Obras Completas de San Agustín. Madrid: La Editorial Catolica/BAC, 1963, tomo III, I, 2, 5.
} 
Neste sentido, para cada função da mente Agostinho concebe a existência de um princípio de estabilidade: para a razão é a Verdade, para a memória a Eternidade e para a vontade a união de ambas. Por isso, a esta última cabe garantir o repouso do ser, sua estabilidade na Ordem. Sendo assim a consequência mais profunda do desejo desenfreado é o desequilíbrio das operações no interior da alma. Para Agostinho a Sabedoria consiste em integrar de forma pacífica e salutar todos os conteúdos anímicos, inclusive a tendência dispersiva das paixões, diretamente vinculadas às operações de nível sensorial. $\mathrm{Na}$ sua antropologia as paixões tendem, por natureza, a se fixarem nas coisas amando-as. Para que não seja dominado por aquilo que lhe advém pelos sentidos e paixões neste processo, o homem precisa que em sua estrutura interna haja um elemento capaz de garantir-lhe a preservação da ordem natural, esta é a função da razão ${ }^{26}$, por isso, sábios são "aqueles que a Verdade manda chamar, isto é, aos que estão pacificados, uma vez subjugadas todas as paixões ao reino da mente" 27 .

Contudo, dita condição da natureza humana no tempo é agravada pela concupiscência que transforma as paixões numa força que a própria razão tem dificuldades para controlar. Esta é uma percepção já presente em De libero arbitrio, mas que será mais enfaticamente desenvolvida por Agostinho a partir de suas interpretações das cartas paulinas, e nelas, do tema do pecado original, do que Ad Simplicianum é considerado por Dodaro ${ }^{28}$ a primeira obra de grande impacto.

\subsection{O livre arbitrio: a capacidade humana de transcender}

No centro da questão sobre a origem do mal em Agostinho está o fato de que esta pax anima só pode ser desfeita pela operação de uma faculdade - o livre arbítrio da vontade. Estando a mente do sábio devidamente pacificada em conformidade com o que reza a lei eterna, "nenhuma outra realidade torna a mente companheira do desejo desenfreado senão a própria vontade e o livre arbítrio" ${ }^{29}$. Em razão do livre arbítrio o homem tem a

\footnotetext{
${ }^{26}$ É clara aqui a semelhança do pensamento agostiniano com a synkatathesis estóica, a saber, o assentimento a uma impressão sensória exterior representada proporcionalmente, como um bem (ou um mal) para o ser humano, conforme afirma CARY, P. Augustine's Invention of the inner self: The legacy of a Cristian Platonist. Oxford: University Press, 2000, p. 155.

${ }^{27}$ AGOSTINHO. Diálogo sobre o Livre Arbitrio. Lisboa: Centro de Filosofia da Universidade de Lisboa: Imprensa Nacional-Casa da Moeda, 2001, I, 9,19.

${ }^{28}$ DODARO, R. Cristo e a sociedade justa no pensamento de Agostinho. Curitiba: Scripta Publicações, 2014, p. 122.

${ }^{29}$ AGOSTINHO. Diálogo sobre o Livre Arbitrio. Lisboa: Centro de Filosofia da Universidade de Lisboa: Imprensa Nacional-Casa da Moeda, 2001, I, 11, 21.
} 
possibilidade de voluntariamente manifestar ou não a bondade e a Sabedoria do Criador em coerência com a Verdade. Em última análise é neste movimento voluntário que Agostinho fundamenta a origem do mal. Comenta Ricoeur que sob sua forma de compreensão da realidade e da ação humana nela, está a ideia de que "Deus cria o homem como liberdade finita; a finitude desta liberdade significa que ela está originariamente orientada $[\ldots]$ por meio de um princípio de hierarquização e de preferência entre valores; e esta estrutura ética da liberdade é o que constitui a autoridade mesma dos valores" ${ }^{\prime 30}$.

O movimento que dá origem ao mal ocorre quando a vontade consente no exercício de seu livre arbítrio ao apelo desordenado das paixões, determinando assim a formação de uma realidade negativa no interior da alma, a qual é sedimentada por hábitos e sentimentos contrários às suas virtudes e, sobretudo, à Verdade. Portanto, não é no cosmos, nem na natureza que está a origem do mal, mas unicamente na ação, no consentimento interno da alma que cria uma mala voluntas. É na forma como decidimos, por meio de uma operação mental coordenar nossa possibilidade de escolha sobre o mundo que Agostinho fixa o "problema do mal" afirmando que sua origem "reside efetivamente na alma, no consentimento que é pecado, portanto, um mal, que acontece em uma substância boa [...], todavia, em virtude deste mal passa a se chamar também má, a alma" ${ }^{\prime 1}$. Em cada ação o homem precisa discernir em sua mente entre ambas as possibilidades de ser que o mundo lhe apresenta, o que cabe à razão, e escolher por uma delas, o que cabe à vontade livre. Com isso ele pode transcender não apenas as leis da natureza, pode até negar as leis divinas.

Desta feita em Agostinho a "qualificação" de uma ação moral como boa ou má está diretamente atrelada à estrutura interna do sujeito e seu funcionamento, ou seja, em última análise o que qualifica a ação moral não é a natureza do objeto desejado, esta é sempre boa porque criada, mas a forma como o ser humano faz sua escolha coordenada no interior da mente. A falta é cometida primariamente no foro íntimo da alma, pelo que cabe unicamente ao homem a origem do princípio de responsabilização por suas consequências. Visto deste ângulo, o problema do mal é sempre compreendido no horizonte da "primeira pessoa", pois, no limite, a ação voluntária é primariamente a atitude subjetiva de um indivíduo na relação consigo. Neste sentido, irá afirmar Agostinho que "quando a alma sofre da parte de suas próprias atividades, o sofre por influxo de si

\footnotetext{
${ }^{30}$ RICOUER, P. Finitud e Culpabilidad. 2. ed.. Madrid, Editorial Trotta, 2011, p. 391.

31 AgOSTINHO. Respuesta a Secundino. In: Obras Completas de San Agustín. Madrid: La Editorial Católica/BAC, 1986, tomo XXX, XV.
} 
mesma, não por influência do corpo, pois se adapta por inteiro ao corpo. E por esta razão se apequena em si mesma"32.

Contudo, vista desta forma a vontade agostiniana não pode ser considerada (para usar um termo em sentido nietzscheano) pura vontade de poder. Isto pelo fato de que ela não é produtora de ser frente ao nada, mas está inserida na Ordem de um universo que é ser (esse) anterior e maior do que ela, a saber, ela é parte da criação que se sustenta sob um fundamento - Deus. Mesmo o desejo de um bem menor é um ato livre de ser, portanto, mesmo a ação defectível também manifesta certa ordem porque tem sua origem na vontade, embora sua conclusão seja a formação de uma desordem. Não é possível no universo agostiniano a existência de qualquer forma de relação ontológica esvaziada de ser, isto é, entregue à lógica extrema da contingência; toda ação sempre acontece dentro dos limites da Ordem, e a vontade não é a absoluta produtora dela. Quando diz que o mal “é nada”, Agostinho não está dizendo que ele derive de uma relação em que um dos polos se sustente pela total ausência de realidade, que não tenha forma, no sentido platônico do termo; isto seria uma contradição lógica. Ao contrário, o mal nasce de uma relação entre dois polos da ordem do ser onde um deles, a vontade, possui o livre arbítrio, por isso seu resultado é sempre "alguma coisa" ainda que seja levar um dos seres à defectibilidade. Em sua visão conceber a vontade no nível de uma completa indeterminação seria o mesmo que equipara-la à vontade criadora de Deus, mais ainda, aplicar tal noção a uma faculdade temporal seria o mesmo que conceber ao nada um estatuto que ele não possui.

Esta natureza essencialmente dinâmica da vontade em Agostinho precisa ser compreendida à luz da intentio animi ${ }^{33}$. Ela diz respeito à forma como a natureza da mente se articula em relação a si própria, ao mundo e a Deus. Na intentio animi, a mente se move em um domínio reflexivo pelo qual percebe o real sempre qualificado. Para a alma isto significa sua tendência inexorável de posse dos bens que se completa na tendência da vontade ao ser. Logo, o ponto chave do problema moral que está na questão da responsabilidade pela origem do mal, encontra sua origem na capacidade humana de

\footnotetext{
${ }^{32}$ AGOSTINHO. De Musica. In: Obras completas de Saint Agustín. Madrid: La Editorial Católica/BAC, 1988, tomo XXXIV, VI, 5, 12.

${ }^{33} \mathrm{Em}$ Agostinho este conceito explica o duplo movimento da mens em que a alma desvela e constrói sua identidade. Pela intentio animi pode-se compreender tanto a relação da alma com o exterior, como o movimento dela para o interior de si mesma e para a realidade que a transcende, a intentio animi demonstra como Agostinho concebe a estrutura psicossomática do ser humano. Sobre este ponto ver ainda MAGNAVACCA, S. El tiempo como ámbito de construcción metafísica en Agustín. In: REEGEN, J. T.; DE BONI, L. A.; COSTA, M. (org.) Tempo e Eternidade na Idade Média. Porto Alegre: EST, 2007, p. 4356.
} 
produzir uma boa ou uma má vontade. É preciso ter claro no entanto, que em Agostinho a consciência da lei racional evita que a ética seja reduzida a uma espécie de decisionismo ou voluntarismo, uma decisão pelo irracional é irracional porque é contrária à natureza em função do conhecimento e da consciência da lei eterna, por isso, que o conceito de vontade agostiniano possui inerente a si um caráter normativo às suas funções morais.

\section{A formação da bona voluntas: $O$ ordenamento da vontade pelas virtudes}

Para Agostinho a boa vontade é o maior bem da natureza humana porque lhe permite possuir em plenitude aquele Bem que ultrapassa todos os bens. Em De libero arbitrio e outros escritos contra o maniqueísmo ele conecta a obtenção dela diretamente ao cultivo das virtudes ${ }^{34}$ que servem como uma mediação para que com os ditames da razão desenvolvamos a boa vontade na alma. Nesta perspectiva em (De lib. arb. I, 13, 27) a prudência é definida como o conhecimento das verdades que se devem desejar e as que se devem evitar; a fortaleza como um estado de alma pelo qual desprezamos os incômodos e a perda das realidades que não podemos controlar; a temperança como a repressão dos desejos indecorosos, e a justiça como a virtude pela qual se desenvolve a capacidade de dar a cada um o que lhe compete. Em outra obra de caráter apologético e que data do mesmo contexto, o opúsculo De Moribus Ecclesiae Catholicae et de Moribus Manichaeorum, tais virtudes morais são definidas em conexão com o conceito de amor. Neste texto a virtude nada mais é do que o caminho que conduz a alma à felicidade e sua definição mais elementar é um perfeito amor a Deus e a sua lei. Assim, quanto às virtudes diz-se que

sua quádrupla divisão não expressa mais do que vários afetos de um mesmo amor, e é por isso que não duvido ao definir as quatro virtudes como distintas funções do amor. A temperança é o amor que totalmente se entrega ao objeto amado; a fortaleza é o amor que a tudo suporta pelo objeto de seus amores; a justiça é o amor unicamente escravo de seu amado e que exerce, portanto, senhorio conforme a razão; e finalmente, a prudência é o amor que com sagacidade e sabedoria, elege os meios de defesa contra toda classe de obstáculos ${ }^{35}$.

Em Agostinho o amor-virtude designa a força primária e mais nobre pela qual o homem estabelece relações com o mundo, se refere aquilo que é produzido na relação de

\footnotetext{
${ }^{34}$ Em De libero arbitrio Agostinho toma o conceito de virtude basicamente como uma disposição desiderativo-cognitiva presente na alma quando o intelecto observa a boa lei presente na alma, isto é, a lei eterna. Já em suas obras mais tardias, como em (De Civ. Dei, XIV, 7), ele fala de uma boa vontade formada a partir do cultivo das virtudes cristãs, especificamente da caritas.

${ }^{35}$ AGOSTINHO. De los Costumbres de la Iglesia Católica. In: Obras Completas de San Agustín. Madrid: La Editorial Católica/BAC, 1956, tomo IV, I, 15, 25.
} 
troca estabelecida entre o homem e outro ser, por isso para o autor todas as relações humanas dependem da relação amorosa do homem com Deus. Exatamente este ponto é o que marca o princípio de seu distanciamento do estoicismo romano, pois o bem da virtude deixa de ser o fim último da ação que passa a ser "estar em Deus". Neste amor fundamental encontra-se o princípio que em sua visão torna as virtudes morais o acabamento da formação de uma boa vontade, pois o homem virtuoso é aquele que sabe como amar compreendendo que Deus enquanto Sumo Bem se sobrepõe a todos os seres na Ordem da realidade. O homem virtuoso é aquele que "possui a temperança enquanto não deseja os bens deste mundo, e a fortaleza, enquanto deles se desapega" ${ }^{36}$. Assim, temse a formação de uma boa vontade quando amando com retidão a alma se torna capaz de desfrutar do bem das virtudes. Afirma Agostinho que

\begin{abstract}
não será dotado de nenhuma prudência aquele que não vê que este bem deve ser desejado, e que se devem evitar as realidades que se lhe opõem [...]. Não entendo que outro homem se possa chamar de forte com mais verdade, a não ser aquele que suporta, com igualdade e tranquilidade de espírito, a privação daquelas realidades cuja aquisição e conquista não depende de nós [...]. Compreendes perfeitamente que o homem que ama a sua boa vontade se opõe e resiste em absoluto às paixões. Portanto, dir-se-á com justiça que ele pratica a temperança [...]. Aquele que possui e ama a boa vontade, e que, como se disse, se opõe às coisas que são inimigas dela, não pode querer mal a ninguém. Seguese, portanto que a ninguém faz injúria, o que de modo algum pode acontecer, a não ser que dê a cada um aquilo que lhe é devido. E quando eu disse que isto pertencia à justiça, tu aprovaste como julgo que recordas ${ }^{37}$.
\end{abstract}

Como visto o conceito agostiniano de "amor" difere radicalmente da forma moderna como o concebemos sob a influência do romantismo. Agostinho pensa não no estado emocional do amor, mas na caritas (amor como dilectio), uma força motriz da alma humana que conecta as virtudes com um bem pretendido sob a égide de um telos cuja origem é a relação amorosa com Deus. "Amor" é um terminus technicus em termos de teoria do desejo e significa tanto quanto "tendência", "direcionamento", "inclinação". As virtudes garantem com isso, o direcionamento duradouro de uma pessoa a um bem" ${ }^{38}$. A presença das virtudes na alma segue o mesmo sentido da que a alma possui em relação ao corpo; delas depende a "qualidade da intenção" em que se projeta a vontade, o que é definido pela forma como amamos as coisas criadas. Neste sentido que diz Agostinho: “não é pelo fato de terem querido a vida feliz que são felizes - com efeito, isto também

\footnotetext{
${ }^{36}$ AGOSTINHO. De los Costumbres de la Iglesia Católica. In: Obras Completas de San Agustín. Madrid: La Editorial Católica/BAC, 1956, tomo IV, I, 22, 40.

${ }^{37}$ AGOSTINHO. Diálogo sobre o Livre Arbitrio. Lisboa: Centro de Filosofia da Universidade de Lisboa: Imprensa Nacional-Casa da Moeda, 2001, I, 13, 27.

${ }^{38}$ HORN, C. Agostinho: conhecimento, linguagem e ética. Porto Alegre: EDIPUC, 2008, p. 153-154. Sobre este ver ainda a obra de PAGLIACCI, D. Volere e Amare: Agostino e la conversione del desidero. Roma: Città Nuova Editrice, 2003.
} 
querem os maus - mas por quererem viver retamente" 39 . Em síntese, o homem realiza a plenitude do bem de sua natureza pelo bom exercício de suas faculdades anímicas, precisamente quando consegue orientar sua vontade sob a égide do conteúdo racional da Verdade em consonância com as virtudes morais que lhe ajudam na adequação de sua alma à lei eterna, e se não o fizer, é diretamente responsável pelo mal produzido a partir do seu interior.

A linha mestra em que Agostinho concebe a vontade a define como "um movimento da alma isento de toda coação, dirigido a não perder ou a conseguir algo" ${ }^{40}$. Já dizia Gilson $^{41}$ que na psicologia de Santo Agostinho a vontade não é geradora de representações, mas copuladora, isto é, tem a função de aplicar nossas faculdades de sentir, imaginar e de pensar aos seus atos, ou então, de desviá-las, por isso que Agostinho restringe ao movimento intencional da vontade o critério mais forte sobre o qual se pode imputar culpabilidade a um agente moral ${ }^{42}$. Do mal que é sinônimo de queda e de esvaziamento ontológico, o homem não pode culpar a ninguém senão a si próprio.

Para que o homem seja perverso a causa deve estar nele mesmo, em algum outro ou em nada. Se está no nada, não há causa. Se está no nada, não existe causa alguma [...]. Se for pela sedução, ela não obriga a quem não quer, assim a causa de sua perversão volta-se à vontade mesma do homem, que passa a ser pervertido com ou sem um sedutor ${ }^{43}$.

Portanto, dado que a culpa pelo sofrimento experimentado na alma está nela mesma, precisamente no livre arbítrio da vontade que a escraviza em desejos culposos, Agostinho tem o cuidado de distingui-lo da autêntica liberdade. Esta não se reduz à capacidade de escolha que a alma tem garantida pelo livre arbítrio, consiste acima de tudo em um "estado de ser" da alma que manifesta equilíbrio e ordem entre suas faculdades, do que redunda à alma não ser escrava nem dos bens alheios a si nem do efeito deleitante que eles suscitam mediante as paixões, logo, em sua visão "a liberdade só é verdadeira para os que são felizes e aderem à lei eterna" ${ }^{\text {44 }}$. A coerência a ela é o que garante ao homem

\footnotetext{
${ }^{39}$ AGOSTINHO. Diálogo sobre o Livre Arbitrio. Lisboa: Centro de Filosofia da Universidade de Lisboa: Imprensa Nacional-Casa da Moeda, 2001, I, 14, 30.

${ }^{40}$ AGOSTINHO. Las dos Almas. In: Obras Completas de San Agustín. Madrid: La Editorial Catolica/BAC, 1986, tomo XXX, I, 14.

${ }^{41}$ GILSON, E. Introdução ao estudo de Santo Agostinho. 2.ed. São Paulo, Paulus, 2010, p. 258.

${ }^{42}$ Segundo BIGNOTTO, N. O Conflito das liberdades: Santo Agostinho. In: Revista Sintese Nova Fase. Belo Horizonte: FAFICH, v. 19, n 58, p. 327-359, 1992, p. 330, para Agostinho em sua busca de uma vida moral perfeita, o homem tem Deus como referência e não mais a cidade. Buscando valores que serão reconhecidos fora da cidade, ainda que suas ações se desenrolem dentro de seus limites, o homem terá apenas sua própria consciência como juiz.

${ }^{43}$ AGOSTINHO. Ochenta y tres cuestiones diversas. In: Obras completas de Saint Agustín. Madrid: La Editorial Católica/BAC, 1995, tomo XL, IV.

${ }^{44}$ AGOSTINHO. Diálogo sobre o Livre Arbitrio. Lisboa: Centro de Filosofia da Universidade de Lisboa: Imprensa Nacional-Casa da Moeda, 2001, I, 15, 32.
} 
uma liberdade diferente da que o limita à possibilidade de se livrar dos outros homens como seus senhores. Esta liberdade experimentamos nas instituições em que se organiza a vida social, onde a lei temporal tem um poder judicativo que "não se estende para além de proibir ou retirar isto ou aquilo àqueles que ela pune. Portanto, é pelo medo que a lei temporal obriga a fazer o que ela quer" ${ }^{\prime 5}$. Em contraste, a lei eterna é propositiva, visa o ordenamento e o crescimento do ser, aponta à alma o horizonte de seu aperfeiçoamento; se por ela a vontade agisse "não haveria castigo, quer por agravo, quer por uma vindica que se impõe aos homens, se eles não amassem aquelas realidades que podem ser-lhe arrebatadas" $"$.

Desfeita a ordem desfaz-se igualmente a experiência de liberdade. Neste estado a lei temporal torna-se "um peso" para a alma, sobretudo na medida em que passa a ter um caráter essencialmente "repressor" em relação ao desejo mais forte que se forma em seu interior. O homem prossegue capaz de fazer escolhas e estabelecer relações, todavia, afastada a vontade da lei eterna, o horizonte destas escolhas e, por conseguinte, a natureza de suas relações, ficam comprometidos em uma situação de pecado. Nela as leis positivas prescrevem como e quando ações são morais ou legais, mas não necessariamente atingem o nível de uma confluência entre o moral no sentido legal e o moral segundo a natureza da ação; uma lei civil pode ser praticada com ou sem paixão e não precisa remeter-se à natureza da paixão, isto é, ao fundamento da ação para garantir seu caráter legal, porém, necessita ser remetida a ele para garantir sua qualidade moral e coerência com a Verdade. Isto quer dizer que em Agostinho "a lei divina se relaciona primariamente com a qualidade da ação, embora inclua secundariamente a lei civil"47.

Em última análise a origem do erro moral não se reduz ao “querer pecar”, pois envolve o engano em relação aquilo que é vantajoso e correto, o que é fruto dos hábitos já corrompidos, da má compreensão em relação aos estímulos produzidos pelos objetos e fatos do mundo. Por isso, a causa do mal não é uma inclinação inata do indivíduo, mas a promoção de um auto engano que se produz no interior da própria alma. Em outras palavras, o pecado é o que há de mais irracional na realidade humana porque pecar não é simplesmente um erro natural, mas uma ação deliberada do sujeito que compromete

\footnotetext{
${ }^{45}$ AGOSTINHO. Diálogo sobre o Livre Arbitrio. Lisboa: Centro de Filosofia da Universidade de Lisboa: Imprensa Nacional-Casa da Moeda, 2001, I, 15,32.

${ }^{46}$ AGOSTINHO. Diálogo sobre o Livre Arbitrio. Lisboa: Centro de Filosofia da Universidade de Lisboa: Imprensa Nacional-Casa da Moeda, 2001, I, 15, 33.

${ }^{47}$ PICH, R. H. Agostinho e a "descoberta" da vontade: primeiro estudo. In: Veritas. Porto Alegre, v.50, n.2, p. 175-206, 2005, p. 192.
} 
ontologicamente sua natureza. Ele produz um estado de natureza que passa a definir o modo como o homem se comporta, sua situação perante seus pares e, sobretudo, perante Deus.

Agostinho conclui sua investigação sobre a origem do mal em De libero arbitrio afirmando que "a mente não pode ser deposta das alturas onde domina, e da recta Ordem, por nenhuma outra realidade a não ser pela vontade [...], nada há nas coisas que se deva inculpar, apenas o mau uso da vontade que deve ser acusado"48. Mais adiante, ele corrobora esta afirmação dizendo que

o homem não passou do bem substancial ao mal substancial, porque nenhuma substância é má. Mas passou do bem eterno ao bem temporal, do bem espiritual ao bem carnal, do bem inteligível ao bem sensível, do Sumo Bem ao bem ínfimo. Existe, pois, um bem que a alma racional não pode amar, sem pecar. É o bem que é inferior a ela. Assim, o mal é o próprio pecado; e não o objeto amado com afeição pecaminosa ${ }^{49}$.

Em Agostinho antes de produzir um ato o mal é um enfraquecimento da alma em relação à sua natureza primeva. A má vontade gera desejos desregrados que quando vividos se tornam um hábito (consuetudo) que vira necessidade, é este movimento da própria alma e não a ação de um ser exterior que a torna escrava do pecado. Assim, enquanto privação a má vontade é uma forma de ausência de algo próprio da natureza, por isso não se devem procurar causas eficientes para as privações da alma, seria o mesmo que querer ver as trevas por si mesmas esquecendo que nada mais são do que a ausência de luz. A irracionalidade que produz a má vontade é a mesma que gera o crepúsculo do bem na alma, esvaziando sua natureza e tirando-lhe o gozo que vem do cultivo das virtudes. Este estado de ser que Agostinho chama "realidade de pecado" é o trágico produto da escolha que o próprio homem faz contra sua natureza. Como ao mesmo tempo ela é uma aversio Dei, é no interior da alma que está a origem do princípio de responsabilidade moral pela culpa que redunda dos atos humanos.

\section{Conclusão}

Na teoria agostiniana aqui exposta vê-se a evidência da vontade livre e sua primazia nas ações do homem. Ao identificar a liberdade da vontade como causa do mal, Agostinho condiciona a confissão da consciência do mal à consciência de liberdade: "o mal existe

\footnotetext{
${ }^{48}$ AGOSTINHO. Diálogo sobre o Livre Arbitrio. Lisboa: Centro de Filosofia da Universidade de Lisboa: Imprensa Nacional-Casa da Moeda, 2001, I, 16, 34.

${ }^{49}$ AGOSTINHO. A Verdadeira Religião. 2 ed. São Paulo: Paulus, 2007, p. 25-138.
} 
porque sou livre". Com esta confissão o entendimento não só da realidade humana em sua facticidade, mas, sobretudo, a compreensão do mundo a partir de uma teodiceia é explicada desde a capacidade do homem de agir com liberdade e da possibilidade de sua alma articular um movimento "irracional" dissonante à Ordem e averso a Deus.

Segundo Horn ${ }^{50}$ é vasta na História da Filosofia Ocidental a literatura que atribui a Agostinho a dádiva de ser o inventor do conceito moderno de vontade. Em comum a estas posições, está a ideia de que há uma diferença fundamental entre uma representação pré cristã de voluntariedade ${ }^{51}$ e uma representação cristã de responsabilidade moral do sujeito dotado de liberdade. Em linhas gerais a filosofia grega reduz o bom agir ao conhecimento racional e atrela o mal agir a influência dos afetos. Já a vontade agostiniana aparece num primeiro momento alheia a toda grandeza que possa determiná-la, é um elemento anímico que não pode se reduzir nem ao âmbito das paixões nem à razão. É uma faculdade independente suscetível tanto a um bom quanto a um mau uso. A vontade à qual se atrela a ação do livre arbítrio, toma uma decisão a qual não podem ser imputadas causas posteriores; ela não se identifica nem com a razão nem com as paixões, porque é antes de tudo uma potência para que se realize uma escolha entre opções irracionais ou racionais.

No primeiro livro de De libero arbitrio a vontade tem as características de uma potência que está de modo imediato em posse de seu portador, a partir do que se configura aquele "espaço do mundo" do qual cada indivíduo é sempre dono e senhor. A qualidade da ação humana no plano da natureza se define, stricto sensu, pelo equilíbrio que o homem consegue encontrar entre a dimensão potencial e a intencional de sua alma. Em visão agostiniana, por este equilíbrio cada indivíduo forja seu mundo sabendo que arrasta sempre consigo, em cada um de seus atos, de algum modo, o universo inteiro. Na relação entre o potencial e o intencional que tem na vontade seu núcleo gerador, o âmbito singular se entrecruza com o universal na qualificação da ação de cada homem, que mesmo situado numa determinada condição histórica, não pode, pela constituição de sua natureza, eximir-se da responsabilidade sobre ela e, especialmente, sobre si mesmo.

A vontade geradora de ser de Santo Agostinho possui certa primazia sobre as outras faculdades anímicas porque em última análise é a partir da escolha gerada por ela, que não somente a qualidade da ação individual de cada homem se define, mas também seu estado de ser no mundo e perante Deus. Ainda que Agostinho reconheça poder haver

\footnotetext{
${ }^{50}$ HORN, C. Agostinho: conhecimento, linguagem e ética. Porto Alegre: EDIPUC, 2008, p. 120.
}

${ }^{51}$ ARISTÓTELES. Ética a Nicômaco. 4 ed. São Paulo: Edipro, 2018, III. 
certo nível de fragilidade na qualidade do discernimento racional dos homens, é à vontade, uma faculdade de pleno domínio de cada indivíduo, que ele confere a origem da direção de cada ação e seus efeitos, pelo que em sua teoria a noção de responsabilidade é sempre um problema individual, restrito à consciência de quem decide. É, portanto, da responsabilidade de cada homem, além dos efeitos exteriores de cada decisão tomada, a responsabilidade pela qualidade interior de sua mente, de seus princípios, enfim, de todo universo anímico em que tem vida a vontade.

\section{Referências}

AGOSTINHO. A Cidade de Deus. 2. ed. Lisboa: Fundação Calouste Gulbenkian, 2000.

AGOSTINHO. Confissões. 2. ed. Lisboa: Centro de Literatura e Cultura Portuguesa e Brasileira: Imprensa Nacional - Casa da Moeda, 2004.

AGOSTINHO. Ochenta y tres cuestiones diversas. In: Obras completas de Saint Agustín. Madrid: La Editorial Católica/BAC, 1995, tomo XL.

AGOSTINHO. Solilóquios. 4. ed. São Paulo: Paulus: 2010.

AGOSTINHO. A Verdadeira Religião. 2. ed. São Paulo: Paulus, 2007.

AGOSTINHO. A Continência. São Paulo: Paulus: 2013.

AGOSTINHO. Las dos Almas. In: Obras Completas de San Agustín. Madrid: La Editorial Catolica/BAC, 1986, tomo XXX.

AGOSTINHO. Respuesta a Secundino. In: Obras Completas de San Agustín. Madrid: La Editorial Católica/BAC, 1986, tomo XXX.

AGOSTINHO. Sobre diversas cuestiones a Simpliciano. In: Obras Completas de San Agustín. Madrid: La Editorial Católica/BAC, 1952, tomo IX.

AGOSTINHO. De Musica. In: Obras completas de Saint Agustín. Madrid: La Editorial Católica/BAC, 1988, tomo XXXIV.

AGOSTINHO. De los Costumbres de la Iglesia Católica. In: Obras Completas de San Agustín. Madrid: La Editorial Católica/BAC, 1956, tomo IV.

AGOSTINHO. Contra Academicos. In: Obras Completas de San Agustín. 3. ed. Madrid: La Editorial Catolica/BAC, 1963, tomo III.

AGOSTINHO. Diálogo sobre o Livre Arbítrio. Lisboa: Centro de Filosofia da Universidade de Lisboa: Imprensa Nacional-Casa da Moeda, 2001. 
AGOSTINHO. La inmortalidad del alma. In: www.augustinus.it/spanolo.

ARISTÓTELES. Ética a Nicômaco. 4. ed. São Paulo: Edipro, 2018.

AYOUB, C. N. A. Iluminação trinitária em Santo Agostinho. São Paulo: Paulus, 2011.

BIGNOTTO, N. O Conflito das liberdades: Santo Agostinho. In: Revista Sintese Nova Fase. Belo Horizonte: FAFICH, v. 19, n 58, p. 327-359, 1992.

BIOLO, S. L'Autoconscienza in S. Agostino. In: Analecta Gregoriana. v.172, n.15. Roma: Editrice Pontificia Università Gregoriana, 2000.

CARY, P. Augustine's Invention of the Inner Self: The legacy of a Cristian Platonist. Oxford: University Press.

DE CAPITANI, F. Quid et unde malum - Il problema Del male nel Giovane Agostino, prima Del ritiro a Cassiciaco. In: V Seminario del Centro di Studo Agostiniani do Perugia - "Il Misterio del Male e la Libertà: littura dei dialoghi do Agostino. Roma: Instituto Patristicum Agostinianum, 1994, p. 57-80.

DODARO, R. Cristo e a sociedade justa no pensamento de Agostinho. Curitiba: Scripta Publicações, 2014.

EVANS, G. R. Agostinho sobre o Mal. São Paulo: Paulus, 1995.

GILSON, E. Introdução ao estudo de Santo Agostinho. 2. ed. São Paulo: Paulus, 2010.

HORN, C. Agostinho: conhecimento, linguagem e ética. Porto Alegre: EDIPUC, 2008.

LEVERING, M. The Theology of Augustine: An Introduction Guide to His Most Important Works. Michigan: Baker Academic, 2013.

MAGNAVACCA, S. El tiempo como ámbito de construcción metafísica en Agustín. In: REEGEN, J. T.; DE BONI, L. A.; COSTA, M. (org.) Tempo e Eternidade na Idade Média. Porto Alegre: EST, 2007, p. 15-35.

MEAGHER, R. Augustine: On the Inner Life of the Mind. Indianapolis: Hackett Dublishing Company, 1998.

OLIVEIRA E SILVA, P. Ordem e Ser: ontologia da Relação em Santo Agostinho. Lisboa: Centro de Filosofia da Universidade de Lisboa, 2007.

OLIVEIRA E SILVA, P. Introdução ao Diálogo sobre o Livre Arbítrio. In: AGOSTINHO. Diálogo sobre o Livre Arbitrio. Lisboa: Centro de Filosofia da Universidade de Lisboa: Imprensa Nacional-Casa da Moeda, 2001, p. 13-76.

O’CONNEL, R. J. De libero arbitrio I: Stoicism revisited. In: Augustian Studies I (1970), p. 49-68. 
PAGLIACCI, D. Volere e Amare: Agostino e la conversione del desidero. Roma: Città Nuova Editrice, 2003.

PICH, R. H. Agostinho e a "descoberta" da vontade: Primeiro estudo. In: Veritas. Porto Alegre, v.50, n.2, p. 175-206, 2005 A.

PICH, R. H. Agostinho e a "descoberta" da vontade: primeiro estudo. In: Veritas. Porto Alegre, v.50, n.3, p. 139-158, 2005 B.

RICOEUR, Paul. Finitud e Culpabilidad. 2. ed. Madrid, Editorial Trotta, 2011.

TORCHIA, N. J. Estoicos, Estoicismo. In: FITZGERALD, A. (org.). Diccionario de San Agustín: San Agustín a traves del tiempo. Burgos: Monte Castelo, 2001. p. 517521.

ULLMANN, R.A. Plotino: Um estudo das Enéadas. 2. ed. Porto Alegre: EDIPUCRS, 2008 . 